Adv Funct Mater. 2011 February 22; 21(4): 779-785. doi:10.1002/adfm.201002077.

\title{
Structural Origins of Silk Piezoelectricity
}

\author{
Dr. Tuna Yucel, \\ Department of Biomedical Engineering, Tufts University, Medford, MA 02155 (USA) \\ Prof. Peggy Cebe, and \\ Department of Physics and Astronomy, Tufts University Medford, MA 02155 (USA) \\ Prof. David L. Kaplan \\ Department of Biomedical Engineering, Tufts University, Medford, MA 02155 (USA) \\ David L. Kaplan: david.kaplan@tufts.edu
}

\begin{abstract}
Uniaxially oriented, piezoelectric silk films were prepared by a two-step method that involved: (1) air drying aqueous, regenerated silk fibroin solutions into films, and (2) drawing the silk films to a desired draw ratio. The utility of two different drawing techniques, zone drawing and water immersion drawing were investigated for processing the silk for piezoelectric studies. Silk films zone drawn to a ratio of $\lambda=2.7$ displayed relatively high dynamic shear piezoelectric coefficients of $d_{14}=-1.5 \mathrm{pC} / \mathrm{N}$, corresponding to over two orders of magnitude increase in $d_{14}$ due to film drawing. A strong correlation was observed between the increase in the silk II, $\beta$-sheet content with increasing draw ratio measured by FTIR spectroscopy $\left(C_{\beta} \alpha \mathrm{e}^{2.5 \lambda}\right)$, the concomitant increasing degree of orientation of $\beta$-sheet crystals detected via WAXD $\left(F W H M=0.22^{\circ}\right.$ for $\lambda=$ $2.7)$, and the improvement in silk piezoelectricity $\left(d_{14} \alpha \mathrm{e}^{2.4} \lambda\right)$. Water immersion drawing led to a predominantly silk I structure with a low degree of orientation $\left(F W H M=75^{\circ}\right)$ and a much weaker piezoelectric response compared to zone drawing. Similarly, increasing the $\beta$-sheet crystallinity without inducing crystal alignment, e.g. by methanol treatment, did not result in a significant enhancement of silk piezoelectricity. Overall, a combination of a high degree of silk II, $\beta$-sheet crystallinity and crystalline orientation are prerequisites for a strong piezoelectric effect in silk. Further understanding of the structural origins of silk piezoelectricity will provide important options for future biotechnological and biomedical applications of this protein.
\end{abstract}

\section{Keywords}

Silk; protein; piezoelectricity; structure

\section{Introduction}

Piezoelectricity is the ability of certain crystalline and liquid crystalline materials that lack a center of symmetry to convert mechanical energy into electrical energy or vice versa. Some polymer crystals and liquid crystals ${ }^{[1]}$ also lack a symmetry center and therefore exhibit intrinsic piezoelectricity. ${ }^{[2]}$ Some uniaxially oriented, polycrystalline, biopolymeric materials show intrinsic shear piezoelectricity, i.e., an electrical polarization in response to shear deformation, in a direction perpendicular to the shear field. ${ }^{[3]}$ Shear piezoelectricity in silk fibroin, the structural, self-assembling protein of silkworm fibers, has been the subject of early research. ${ }^{[4-6]}$ To our knowledge, Harvey was the first to attribute the reddish luminescence that forms due to shaking of silk fragments to their piezoelectricity. ${ }^{[6]}$ Fukada, 
et al. conducted the first quantitative measurements on the intrinsic shear piezoelectricity of silk fiber bundles ${ }^{[5]}$ and observed a piezoelectric response of $\sim 1 \mathrm{pC} / \mathrm{N}$, comparable to that of the quartz crystal $(\sim 2 \mathrm{pC} / \mathrm{N})$. In addition, the temperature and water content dependence of the piezoelectric properties of uniaxially oriented silk fibroin films were extensively studied. ${ }^{[4]}$ However, there have not been any reports on silk piezoelectricity over the past three decades, nor any insight into the mechanisms underlying the phenomena observed with silk materials.

Silk fibroin is a high molecular weight block copolymer consisting of a heavy $(\approx 370 \mathrm{kDa})$ and light chain $(\approx 26 \mathrm{kDa})$. These two chains of different amphiphilicity are linked together by a single disulfide bond. ${ }^{[7]}$ The heavy chain predominantly consists of alternating hydrophobic, repetitive oligopeptides that are separated by smaller charged and amorphous sequences. The hydrophobic domain is rich in alanine and glycine amino acids, while the hydrophilic spacers give the heavy chain a polyelectrolyte nature. The sequence of the light chain is less repetitive and contains a high concentration of glutamic and aspartic acid residues. In Nature, the crystalline regions in semicrystalline fibroin fibers assume the silk II form, a pleated, antiparallel $\beta$-sheet secondary structure with a monoclinic unit cell. ${ }^{[8,9]}$ Furthermore, silk fibroin is known to display crystalline polymorphism. One such polymorph, silk $I^{[10]}$ is considered to be a predominantly helical, less extended conformation of silk chains as compared to silk II. With the application of shear, the metastable silk I structure usually transitions into silk II. Silk III, on the other hand, is a three-fold, helical conformation found in thin films at the air-water interface with an overall trigonal unit cell. ${ }^{[11]}$ Silk fibroin has been processed into a variety of material formats, such as electrospun fibers, ${ }^{[12]}$ films, ${ }^{[13]}$ micro-and nano-spheres, ${ }^{[14]}$ hydrogels, ${ }^{[15,}$ 16] adhesives ${ }^{[17,18]}$ and 3 -d porous scaffolds ${ }^{[19]}$ for biomaterials, tissue engineering, and cell/ drug delivery applications. The interest in silk fibroin for biotechnological and biomedical applications stems from the highly controllable $\beta$-sheet content, exceptional mechanical properties, biocompatibility, and controllable biodegradation rates. ${ }^{[20-23]}$ For example, 3-d silk fibroin scaffolds have shown osteogenic ability in vitro ${ }^{[24,25]}$ and osteopromotive potential in critical sized defects in vivo. ${ }^{[26]}$

In this paper, our goal was to provide direct evidence on the structural origins of silk piezoelectricity as controlled by various materials processing parameters including drawing method, draw ratio, and post-draw treatment. For this purpose, we developed a custom setup that enabled drawing of silk films to a desired ratio at high temperatures, termed zonedrawing. We also carried out experiments that involved film drawing at room temperature after immersion in water. For subsequent characterization of molecular structure and possible crystal orientation in silk films, we employed Fourier Transform Infrared Spectroscopy (FTIR) and Wide Angle X-ray Diffraction (WAXD), respectively. To correlate structure with the piezoelectric effect in silk, we coupled a dynamic mechanical analyzer (DMA) with an electrometer. Our goal was to provide an electro-physicochemical basis for silk piezoelectricity for future biomedical applications.

\section{Results and Discussion}

\subsection{Film processing}

Dynamic mechanical analysis was employed to establish a suitable temperature for zone drawing silk fibroin films. Figure 1A shows typical temperature sweeps of the complex dynamic tensile modulus, $E^{*}=E^{\prime}+i E^{\prime \prime}$ (where $E^{\prime}$ is the storage modulus and $E^{\prime \prime}$ is the loss modulus) and the loss tangent, $\tan (\delta)=E^{\prime \prime} / E^{\prime}$ for silk fibroin films. At a heating rate of $5^{\circ} \mathrm{C} / \mathrm{min}, E^{*}$ was essentially constant from room temperature up to approximately $170^{\circ} \mathrm{C}$ and frequency independent (supporting information, Figure $1 \mathrm{~A}$ ). For $T>170^{\circ} \mathrm{C}$ there was a sharp decrease in $E^{*}$ values that indicated an onset of a "glass transition". At this heating 
rate, $\tan (\delta)$ peaked at $190^{\circ} \mathrm{C}$, suggestive of a "glass transition temperature" or $T_{G}$ (Figure 1A). In practice, silk films were too stiff to zone draw at temperatures $<T_{G}$, while attempts to draw films at temperatures $\gg T_{G}$ led to brittle fracture, possibly due to irreversible $\beta$ sheet formation at higher temperatures and subsequent film stiffening (see supporting information, Figure 1B for the time evolution of frequency sweeps of $E^{*}$ during a $200^{\circ} \mathrm{C}$ anneal). Accordingly, a temperature of $190 \pm 3^{\circ} \mathrm{C}$ was found suitable for silk fibroin zone drawing. Using a custom zone drawing setup (Figure 1B, see section 4 for details), silk films were drawn up to a draw ratio of $\lambda=2.7$.

Alternatively, silk films could be drawn at room temperature after immersion of as-dried films in water, which lead to an apparent film softening. This decrease in film stiffness could be attributed to a decrease in the effective $T_{G}$ due to film hydration. ${ }^{[27,28]}$ After water immersion, films could easily be drawn at a constant elongation rate of $10 \mathrm{~mm} / \mathrm{min}$ using a dynamic mechanical analyzer. Using this technique, silk films were drawn up to $\lambda=2.0$. It was not possible to achieve higher draw ratios using water immersion due to formation of cracks, presumably as a result of film drying and subsequent stiffening. Drawing films while still immersed in water should prevent film drying and enable higher draw ratios.

\subsection{Structure}

FTIR spectroscopy was employed to quantify possible effects of processing parameters (draw ratio, draw method and post-draw treatment) on the overall molecular conformation (Figure 2) according to reported $\mathrm{C}=\mathrm{O}$ stretch vibrational band assignments for common protein secondary structures in the amide I region $\left(1600-1700 \mathrm{~cm}^{-1}\right) \cdot{ }^{[29-31]}$ As-dried silk fibroin films displayed broad IR absorption with a single peak at $1641 \mathrm{~cm}^{-1}$ in the amide I region (Figure 2A), typical of a predominantly amorphous conformation. ${ }^{[29]}$ For zone drawn films, the peak position progressively shifted to lower wave numbers with increasing draw ratio and a second peak eventually appeared at $1624 \mathrm{~cm}^{-1}$ for $\lambda=2.7$, indicating the formation of silk II type, $\beta$-sheet rich structures. ${ }^{[29,32]}$ Consequently, the ratio of the absorbance at $1624 \mathrm{~cm}^{-1}$ to that at $1641 \mathrm{~cm}^{-1}\left(C_{\beta}=A_{1624} A_{1641}\right)$ was used to estimate the increase in silk II, $\beta$-sheet content with increasing draw ratio. Corresponding $C_{\beta}$ values were $0.73,0.76,0.93$ and 1.13 for $\lambda=1.0,1.5,2.0$ and 2.7, respectively, for zone drawing. $C_{\beta}$ values were also normalized with respect to the lowest $\left(C_{\beta, \min }\right)$ and highest values $\left(C_{\beta, \max }\right)$

using $\mathrm{C}_{\beta, i}{ }^{\prime}=\frac{\mathrm{C}_{\beta, \max }-\mathrm{C}_{\beta, i}}{\mathrm{C}_{\beta, \max }-\mathrm{C}_{\beta, \min }}$ (this normalization will be used in subsection 2.4 to investigate a possible correlation between the $\beta$-sheet content and the piezoelectric coefficient).

FTIR spectra collected after two post-draw processing steps, namely, annealing of silk films at $200^{\circ} \mathrm{C}$ for one hour $\left(C_{\beta}=1.13\right.$ for $\lambda=2.0$ ) (Figure $2 \mathrm{~A}$ ) and immersion of films in methanol for two days ( $C_{\beta}=1.22$ for $\lambda=2.0$ ), indicated that both treatments led to a further increase in the apparent silk II, $\beta$-sheet content with respect to that for zone drawn films. The increase in $C_{\beta}$ with either treatment could be beneficial for potential biomedical applications that require low biodegradation rates. However, annealing silk films at $200^{\circ} \mathrm{C}$ for extended periods rendered the films too brittle to handle. Therefore, methanol treatment of drawn films could be preferred over film annealing from an application perspective. In contrast with zone drawing, water immersion drawing did not lead to a significant increase in the apparent $\beta$-sheet content (Figure 2B). Water immersion drawn films showed an amide I peak at $1641 \mathrm{~cm}^{-1}$ and a shoulder at $1650 \mathrm{~cm}^{-1}$, in addition to an amide II peak at 1533 $\mathrm{cm}^{-1}$, suggesting a silk I-type structure, ${ }^{[33]}$ a less extended, crystalline polymorph of silk II.

Wide Angle X-ray Diffraction (WAXD) was employed to characterize possible film crystallinity and orientation due to drawing and post-draw treatment (Figure 3). X-ray patterns showed a transition from an essentially amorphous, isotropic structure for as-dried 
films (diffuse halo in Figure 3A) into a $\beta$-sheet crystal structure (silk II) after zone-drawing $(\lambda=2.7)$ (Figure 3B). Annealing of both as-dried (Figure 3C) and zone-drawn films (Figure 3D) at $200^{\circ} \mathrm{C}$ for one hour led to an increase in the degree of crystallinity. Miller plane indices for silk II, $\beta$-sheet crystal peaks were labeled in Figure 3D with corresponding $d$ spacings of $0.95 \mathrm{~nm}(010), 0.43 \mathrm{~nm}(200) /(020), 0.37 \mathrm{~nm}(021) /(201)$ and $0.35 \mathrm{~nm}(002) .{ }^{[34]}$ Methanol treatment of silk films for 48 hours resulted in an increase in film crystallinity similar to that due to annealing (data not shown). On the other hand, water immersion drawn films $(\lambda=2.0)$ showed a strong reflection at $0.72 \mathrm{~nm}$ attributable to the silk I form. ${ }^{[35]}$ At the same draw ratio $(\lambda=2.0)$, the peak positions for zone-drawn films indicated a mixture of silk I $(0.72 \mathrm{~nm})$ and silk II $(0.37 \mathrm{~nm}$ and $0.95 \mathrm{~nm}$ (weak)) structures. The degree of uniaxial, crystal orientation due to film drawing was quantified from the full-width at half maxima $(F W H M)$ calculated from scattered intensity versus azimuthal angle plots (data not shown). A comparison of peak widths for films drawn using different techniques to the same draw ratio $(\lambda=2.0)$ indicated a considerably higher degree of crystalline orientation due to zone drawing $\left(F W H M=27^{\circ}\right)$ as compared to water immersion drawing $\left(F W H M=75^{\circ}\right)$. The degree of orientation increased further with increasing draw ratio for zone drawn films $\left(F W H M=22^{\circ}\right.$ for $\left.\lambda=2.7\right)$

\subsection{Piezoelectric Measurements}

A custom setup was employed for piezoelectric measurements through feeding the strain signal from a dynamic mechanical analyzer and the current signal from an electrometer to a computer through an A/D converter (Figure 4A, see section 4 for further details). A gold sputtered silk fibroin film was placed between the fixtures of the DMA. Each film surface was connected to a different terminal of the electrometer through conductive leads, while electrically insulating the opposite film surface (Figure 4B). In this manner, the dynamic current generated perpendicular to the film plane (along the film thickness) in response to the application of a sinusoidal strain in the plane of the film could be measured.

Figure $4 \mathrm{C}$ shows the waveform data for the time evolution of the piezoelectric current in a zone drawn silk fibroin film $(\lambda=2.7)$. Here, a sinusoidal strain was applied at a measurement angle, $\theta=\pi / 4$, where $\theta$ is defined as the angle between the direction of strain applied by the DMA and the film drawing (orientation) direction in the film plane. A normal displacement of $\pm 1 \mu \mathrm{m}$ (corresponding to a strain of $0.04 \%$ ) at $0.5 \mathrm{~Hz}$ resulted in a shear piezoelectric polarization value of $\pm 10 \mathrm{pC}$ and a potential difference of $\pm 20 \mathrm{mV}$, a value that may be sufficient to affect certain cell behavior. ${ }^{[36]}$

\subsection{Shear piezoelectricity and structure}

Figure 5 shows the dependence of the piezoelectric constant, $d$ on $\theta$. For $\theta=\frac{2 n-1}{4} \pi$ (i.e. the 4 shear direction), $d=d_{\max }$, while $d \rightarrow 0$ for $\theta=\frac{n-1}{2} \pi$ (for integer values of $n$ ). The maxima in the piezoelectric coefficient in the shear direction could arise from the net polarization that could develop in a uniaxially oriented, intrinsically piezoelectric material deformed in shear. ${ }^{[37]}$ Importantly, internal polarizations cancel each other out for other tensors of the deformation matrix. $\left.{ }^{[37]}\right]$ When we assign the $z$-axis as the film drawing axis and the $x$-axis to be perpendicular to the film plane $(y-z)$ in Cartesian coordinates, the direct piezoelectric coefficient matrix consists of eighteen piezoelectric coefficients $\left(d_{i j}\right)$ due to three components of electrical polarization $p_{X}, p_{y}, p_{Z}(i=1,2,3$, respectively) in response to six components of applied stress, $\sigma_{x}, \sigma_{y}, \sigma_{z}, \sigma_{y z}, \sigma_{X z}, \sigma_{x y}(j=1,2,3,4,5,6$, respectively). The sinusoidal form of $d(\theta)$ suggests a piezoelectric coefficient matrix of type 
$D_{\infty}\left(\left[\begin{array}{cccccc}0 & 0 & 0 & d_{14} & 0 & 0 \\ 0 & 0 & 0 & 0 & d_{14} & 0 \\ 0 & 0 & 0 & 0 & 0 & d_{14}\end{array}\right]\right)[3]$ for silk fibroin, commonly observed for intrinsically piezoelectric biopolymers and oriented synthetic polypeptides. ${ }^{[37]}$

Figure 6A shows the dependence of the room temperature shear piezoelectric coefficient $\left(d_{14}\right)$ on the draw ratio $\lambda$ (for zone drawn films), draw method and methanol treatment. The absolute $d_{14}$ values increased exponentially with draw ratio by over two orders of magnitude, from $0.01 \mathrm{pC} / \mathrm{N}$ for as-dried films $(\lambda=1)$ to $1.5 \mathrm{pC} / \mathrm{N}$ for $\lambda=2.7$, in good agreement with previous reports. ${ }^{[4]}$ Measured piezoelectricity values are comparable with the absolute $d_{14}$ values reported previously from highly piezoelectric biopolymers (e.g. oriented collagen, $2-3 \mathrm{pC} / \mathrm{N}$, and cellulose, $0.4-0.9 \mathrm{pC} / \mathrm{N})$, as well as oriented films of synthetic polypeptides, including polyalanine $(\sim 1 \mathrm{pC} / \mathrm{N})$ and poly- $\gamma$-methyl-L-glutamate (PMLG) $(\sim 2 \mathrm{pC} / \mathrm{N}) .{ }^{[38]}$ Furthermore, a relatively low measurement frequency was employed here $(0.5 \mathrm{~Hz})$ as compared to that in the majority of previous reports (10 $\mathrm{Hz}),{ }^{[3,4,37,38]}$ which may have led to an underestimation of silk fibroin piezoelectricity in this paper due to increasing leakage current with decreasing frequency. High intrinsic shear piezoelectric coefficients were also measured from aligned films of synthetic polymers, such as poly-L-lactic acid $(\sim 10 \mathrm{pC} / \mathrm{N}),{ }^{[39]}$ or PMLG oriented under strong magnetic fields $(\sim 4-5$ $\mathrm{pC} / \mathrm{N}){ }^{[40]}$ For comparison, stretched and electrically poled industrial polymers such as poly(vinylidene fluoride), PVDF, reportedly exhibit tensile piezoelectric coefficients of $\sim 30$ $\mathrm{pC} / \mathrm{N}^{[38]}$ that are roughly an order of magnitude higher than the shear piezoelectricity values measured from silk fibroin. However, the all aqueous processability, biocompatibility, controllable biodegradability, and the lack of potentially immunogenic degradation byproducts may render piezoelectric silk a very useful biomaterial for biomedical and biotechnological applications.

To investigate a possible correlation between the silk II, $\beta$-sheet content $\left(C_{\beta}\right)$ and the shear piezoelectric coefficient $\left(d_{14}\right)$, measured values of both parameters $\left(P_{i}\right)$ were normalized with respect to their lowest $\left(P_{\min }\right)$ and highest values $\left(P_{\max }\right)$ using $P_{i}^{\prime}=\frac{P_{\max }-P_{i}}{P_{\max }-P_{\min }}$. Both normalized parameters showed an exponential dependence on the zone draw ratio with very similar exponential factors $\left(C_{\beta^{\prime}} \propto \mathrm{e}^{2.5 \lambda},-d_{14^{\prime}} \propto \mathrm{e}^{2.4 \lambda}\right.$ ) (Figure 6B). These results suggested a strong correlation between shear piezoelectricity and the $\beta$-sheet content. Water immersion drawn silk films exhibited very low shear piezoelectric coefficient values when compared to their zone drawn counterparts $\left(d_{14}=-0.73\right.$ and $-0.05 \mathrm{pC} / \mathrm{N}$ for zone and water immersion drawn films, respectively). Accordingly, the silk I structure with a low degree of orientation observed in water immersion drawn films via FTIR and WAXD did not yield to a strong piezoelectric effect (Figure 7). Similarly, methanol treatment of as-dried films for two days did not result in a significant improvement in silk piezoelectricity as compared with as-dried films, albeit the high $\beta$-sheet crystallinity induced by methanol treatment, in the absence of uniaxial crystal alignment (Figure 7). Overall, we present the first, to our knowledge, direct structural evidence that silk piezoelectricity is due to a combination of high $\beta$-sheet crystal content and crystal orientation (Figure 7). In light of the present structural data, silk piezoelectricity may be explained by net polarization of uniaxially aligned, silk II crystals with a non-centrosymmetric, monoclinic unit cell perpendicular to the plane of the applied shear force. It was hypothesized that shear forces, when applied in the plane of the $\beta$-sheet, could result in intra- and inter-chain slide within pleated $\beta$-sheet domains and a subsequent rotation of amide dipoles, ${ }^{[41]}$ leading to an internal polarization. While an isotropic distribution of $\beta$-sheet crystal domains would lead to a cancellation of internal polarizations, uniaxial orientation of crystal domains could facilitate a net polarization (i.e., a piezoelectric effect). In contrast to previous work, ${ }^{[4]}$ methanol treatment of zone drawn silk films led to a slight decrease in the measured shear 
piezoelectricity values although there was an increase in the apparent degree of crystallinity measured by FTIR and WAXD. Fukada suggested that the value of $d_{14}$ may be proportional to an orientation function and the average of shear piezoelectric coefficients of a single crystal in addition to the degree of crystallinity. ${ }^{[3]}$ Therefore, the drop in silk piezoelectricity values due to methanol treatment may be attributed to the decrease in the orientation function with increasing $\beta$-sheet content. Other drawing methods, such as ethanol immersion drawing may be a convenient, room temperature alternative to zone drawing due to the reportedly high $\beta$-sheet content produced by this drawing method. ${ }^{[42]}$

\section{Conclusions}

Direct structural evidence is provided for the origins of shear piezoelectricity of silk. The results demonstrate that intrinsic silk shear piezoelectricity could be explained on the basis of overall $\beta$-sheet content and uniaxial molecular alignment. Future work could employ the well-established processing toolkit for silk to maximize silk II crystallinity and crystal alignment simultaneously. For example, possible piezoelectricity in silk fibroin electrospun nanofibers as well as possible effects of various processing parameters on the piezoelectric coefficients, such as electrical poling or strong magnetic field alignment, remain to be assessed in this context. Combining the highly controllable crystallinity and biodegradability, mechanical robustness, and biocompatibility of silk with its favorable electromechanical properties may be an interesting route for the sustained engineering of electro-active tissues or related biomaterial applications.

\section{Experimental}

\section{Preparation of Aqueous Silk Fibroin Solutions and Films}

Silk fibroin aqueous solutions were prepared as previously described. ${ }^{[19]}$ Briefly, Bombyx mori cocoons were boiled for $30 \mathrm{~min}$ in an aqueous solution of $0.02 \mathrm{M}$ sodium carbonate and then rinsed thoroughly with deionized (DI) water $(\rho=18.2 \mathrm{M} \Omega \mathrm{cm})$. After overnight drying, the silk fibroin was dissolved in an aqueous solution containing $9.3 \mathrm{M} \mathrm{LiBr}$ at $60^{\circ} \mathrm{C}$ for 4 hours. The solution was dialyzed against DI water using Slide-a Lyzer dialysis cassettes (MWCO 3,500, Fisher Scientific, Pittsburg, PA) for 2 days to remove the residual salt. The final concentration of the silk fibroin was approximately $8 \mathrm{wt} \%$. In a typical experiment, $\sim 100-200 \mu \mathrm{m}$ thick films were prepared by air-drying an appropriate volume of aqueous, regenerated silk solution on $100 \mathrm{~mm}$ diameter polystyrene Petri dishes (Fisher Scientific, Pittsburg, PA). Film thicknesses were measured using a micrometer with resolution to $0.25 \mu \mathrm{m}$.

\section{Zone drawing}

A custom setup was used to draw silk films at high temperature. Samples (typical film dimensions: $50 \mathrm{~mm}$ long and $20 \mathrm{~mm}$ wide) were locally equilibrated at $T=190 \pm 3^{\circ} \mathrm{C}\left(\approx T_{G}\right.$ measured using DMA at an oscillation frequency of $\delta=1 \mathrm{~Hz}$ ) using a temperature control block consisting of two $2 \mathrm{~mm}$ thick, narrow zone heating elements and cooling fans that flanked the sample film from both sides. The heating elements enabled local heating of the sample film and prevented extensive $\beta$-sheet crystallization prior to film drawing. The temperature block was controlled via a temperature controller (PXR4, Fuji Electric Systems, Japan). A linear motion system (Specialty Motions, Inc., CA) was employed to move the temperature control block along the sample film length at approximately $0.1 \mathrm{~mm} / \mathrm{s}$, while approximately 5-10 MPa of stress was simultaneously applied on the film using a pulley to enable film drawing to a desired draw ratio ( $\lambda=$ final length/initial length). 


\section{Water immersion drawing}

Film samples could also be drawn at room temperature after immersion in DI water, due to subsequent film softening. In particular, silk films were kept in DI water for up to 30 minutes. Immediately after hydration, a constant normal elongation rate of $10 \mathrm{~mm} / \mathrm{min}$ was applied using a dynamic mechanical analyzer (RSA 3, TA Instruments, New Castle, DE).

\section{Post-draw treatment}

Control drawn samples were subjected to further treatments such as high temperature $\left(200^{\circ} \mathrm{C}\right)$ annealing in air or in vacuum for up to one hour or methanol treatment, i.e., incubation of the films in methanol for up to two days.

\section{Fourier Transform Infrared Spectroscopy}

The molecular conformation of silk fibroin films was investigated using a JASCO FTIR 6200 spectrometer (JASCO, Tokyo, Japan) equipped with a MIRacle ${ }^{\mathrm{TM}}$ attenuated total reflection (ATR) Ge crystal cell in reflection mode. Air background measurements were taken immediately prior to sample loading and subtracted from the sample reading. Each reported spectrum was the average of 32 scans collected at a resolution of $4 \mathrm{~cm}^{-1}$, for a wave number range from 400 to $4000 \mathrm{~cm}^{-1}$.

\section{Wide Angle X-ray Diffraction}

Room temperature wide angle X-ray diffraction was performed on a Bruker AXS GADDS system equipped with a two-dimensional gas filled wire detector. Intensity was collected for 30 minutes using a $0.5 \mathrm{~mm}$ collimator while the generator was operated at $40 \mathrm{kV}$ and 20 $\mathrm{mA}$. The wavelength was $0.1542 \mathrm{~nm}\left(\mathrm{Cu}-K_{a}\right)$ and the scattering angle, $2 \theta$, was calibrated using sodelite powder as reference standard. Samples were examined in transmission mode with the draw direction of oriented samples placed approximately horizontally.

\section{Dynamic Mechanical Measurements}

The dynamic mechanical properties of silk films were probed using a dynamic mechanical analyzer (RSA3, TA Instruments, New Castle, DE). Dynamic temperature sweeps were collected between room temperature and $200^{\circ} \mathrm{C}$ at an oscillation frequency of $\delta=1 \mathrm{~Hz}$ and a heating rate of $5^{\circ} \mathrm{C} / \mathrm{min}$ to determine the apparent $T_{G}$. Subsequently, dynamic time sweeps were collected at a low strain amplitude $(\gamma=0.01-0.05 \%)$ at temperatures close to the previously reported $\beta$-sheet crystallization temperatures of silk fibroin $\left(\sim 200^{\circ} \mathrm{C}\right)^{[32]}$ to follow the temporal changes in mechanical properties due to annealing.

\section{Dynamic Piezoelectric Measurements}

For piezoelectric coefficient measurements, regular octagonal samples with a span of 5 or 10 $\mathrm{mm}$ were cut from rectangular (as-dried, drawn, or post-draw processed) silk films using titanium scissors. Octagonal samples enabled collection of piezoelectric measurements as a function of 8 measurement angles $(\theta=0, \pm \pi / 4, \pm \pi / 2, \pm 3 \pi / 4, \pi)$ defined here as the angle between the applied strain and the drawing (orientation) direction. Prior to the measurements, $200 \mathrm{~nm}$ thick gold layers were sputter-coated on both film surfaces. A dynamic mechanical analyzer (RSA3, TA Instruments, New Castle, DE) and a programmable electrometer (617, Keithley, Cleveland, $\mathrm{OH}$ ) were employed to measure the dynamic piezoelectric coefficient. The fixtures of the DMA were covered with a high temperature tape to prevent electrical shortage. Electrical contacts were taken from both surfaces of the sample film to the electrometer. Each film surface was in electrical contact with a different terminal of the electrometer through conductive leads. This setup enabled measurement of the current generated perpendicular to the film plane using the electrometer in response to the sinusoidal displacement applied parallel to the film plane using the DMA. 
Under normal operation, the Rheocorr software provided by TA Instruments enables monitoring the real-time, dynamic strain $(\varepsilon)$ and stress $\left(\sigma^{*}\right)$ signals from the DMA through a DAQPad A/D converter (6020E, National Instruments, Austin, TX). The stress and strain signals are cross-correlated to calculate the dynamic tensile modulus $\left(E^{*}=\sigma^{*} / \varepsilon=E^{\prime}+i E^{\prime \prime}\right)$ and the loss tangent $\left(E^{\prime \prime} \mid E^{\prime}\right)$. To enable piezoelectric testing, the current output from the electrometer (instead of the stress output from the DMA in normal operation) was interfaced with Rheocorr through the A/D converter. In this manner, Rheocorr directly displayed the sinusoidal waveform of the applied displacement and an apparent stress response, which in fact was due to the current generated in the film sample. The software then calculated an apparent complex stress from the waveform data. Thus, it was possible to convert the apparent complex stress output from Rheocorr into a complex piezoelectric coefficient, $\left(d^{*}\right.$ $\left.=d^{\prime}-i d^{\prime \prime}\right)$ using a correction factor. All reported piezoelectric measurements were carried out at $\delta=0.5 \mathrm{~Hz}$ frequency and at low strain amplitude within the linear stress-strain regime. The apparent dynamic piezoelectric coefficient was calculated from ${ }^{[2]}$

$$
|d *|=\left(\frac{I}{A_{E}}\right) /\left(\frac{F}{A_{X S}}\right)\left(\mathrm{A} / \mathrm{m}^{2}\right) /\left(\mathrm{N} / \mathrm{m}^{2}\right),
$$

where $I$ is current generated perpendicular to the film plane, $A_{E}$ is the electrode area, $F$ is the force applied in the plane of the film, and $A_{X S}$ is the cross-sectional area. For measurement angle dependence of piezoelectric coefficient $(d(\theta)$ vs. $\theta)$ experiments, the error in $\theta\left(\xi_{\theta}\right)$

was estimated using a sinusoidal fit of the form $d(\theta)=d_{\max } \sin \left(\frac{\theta}{2}+\xi_{\theta}\right)$ using Igor Pro software (Wavemetrics, Inc., Lake Oswego, Oregon), where $d_{\max }$ is the maximum value of the apparent piezoelectric coefficient $\left(d=d_{\max }\right.$ for $\left.\theta=\pi / 4\right)$. For a uniaxially oriented polymer film with class $D_{\infty}, 3 \times 6$ piezoelectric coefficient matrix $\left(d_{14}=-d_{25}, d_{i j}=0\right.$ otherwise), ${ }^{[3]}$ the shear piezoelectric coefficient, $d_{14}$ can be calculated using: ${ }^{[37]}$

$$
d_{14}=\frac{2 d_{\max }}{\sin (2 \theta)}
$$

The limitations in precision for reported $d_{14}$ data were due to limitations in current measurements. The current resolution for reported piezoelectric measurements varied between $1 \mathrm{fA}$ to $10 \mathrm{fA}$, corresponding to a $d_{14}$ resolution of $10^{-4} \mathrm{pC} / \mathrm{N}$ to $10^{-3} \mathrm{pC} / \mathrm{N}$ for typical sample dimensions and applied force values. We reported the $d_{14}$ data to $10^{-2} \mathrm{pC} / \mathrm{N}$ resolution, having at least an order of magnitude higher value than the highest calculated resolution.

\section{Supplementary Material}

Refer to Web version on PubMed Central for supplementary material.

\section{Acknowledgments}

We thank the NIH via the Tissue Resource Center (P41 EB002520), AFOSR and NSF (CBET-0828028) for support of this research. We thank Scott J. McCorkle from Tufts University Machine Shop for his help with manufacturing the zone-drawer. Supporting Information is available online from Wiley InterScience or from the author.

\section{References}

1. Jakli A. Liq Cryst. 37:825. 
2. Hayakawa, R.; Wada, Y. Advances in Polymer Science. CHJ; Ferry, JD.; Natta, G.; Prins, W.; Staverman, AJ., editors. Vol. 11. Springer; New York: 1973. p. 1

3. Fukada E. Q Rev Biophys. 1983; 16:59. [PubMed: 6348831]

4. Ando Y, Okano R, Nishida K, Miyata S, Fukada E. Reports on Progress in Polymer Physics in Japan. 1980; 23:775.

5. Fukada E. J Phys Soc Jpn. 1956; 11:1301.

6. Harvey NE. Science. 1939; 89:460. [PubMed: 17731087]

7. Inoue S, Tanaka K, Arisaka F, Kimura S, Ohtomo K, Mizuno S. J Biol Chem. 2000; 275:40517. [PubMed: 10986287]

8. Lotz B, Cesari FC. Biochimie. 1979; 61:205. [PubMed: 465571]

9. Marsh RE, Corey RB, Pauling L. Biochimica Et Biophysica Acta. 1955; 16:1. [PubMed: 14363226]

10. Kratky O, Schauenstein E, Sekora A. Nature. 1950; 165:319.

11. Valluzzi R, Gido SP, Zhang WP, Muller WS, Kaplan DL. Macromolecules. 1996; 29:8606.

12. Jin HJ, Fridrikh SV, Rutledge GC, Kaplan DL. Biomacromolecules. 2002; 3:1233. [PubMed: 12425660]

13. Jin HJ, Park J, Valluzzi R, Cebe P, Kaplan DL. Biomacromolecules. 2004; 5:711. [PubMed: 15132651]

14. Wang XQ, Yucel T, Lu Q, Hu X, Kaplan DL. Biomaterials. 2010; 31:1025. [PubMed: 19945157]

15. Wang XQ, Kluge JA, Leisk GG, Kaplan DL. Biomaterials. 2008; 29:1054. [PubMed: 18031805]

16. Yucel T, Cebe P, Kaplan DL. Biophysical Journal. 2009; 97:2044. [PubMed: 19804736]

17. Leisk GG, Lo TJ, Yucel T, Lu Q, Kaplan DL. Advanced Materials. 2010; 22:711. [PubMed: 20217775]

18. Yucel T, Kojic N, Leisk GG, Lo TJ, Kaplan DL. Journal of Structural Biology. 2010; 170:406. [PubMed: 20026216]

19. Nazarov R, Jin HJ, Kaplan DL. Biomacromolecules. 2004; 5:718. [PubMed: 15132652]

20. Altman GH, Diaz F, Jakuba C, Calabro T, Horan RL, Chen JS, Lu H, Richmond J, Kaplan DL. Biomaterials. 2003; 24:401. [PubMed: 12423595]

21. Horan RL, Antle K, Collette AL, Huang YZ, Huang J, Moreau JE, Volloch V, Kaplan DL, Altman GH. Biomaterials. 2005; 26:3385. [PubMed: 15621227]

22. Ishida M, Asakura T, Yokoi M, Saito H. Macromolecules. 1990; 23:88.

23. Jin HJ, Kaplan DL. Nature. 2003; 424:1057. [PubMed: 12944968]

24. Kim HJ, Kim UJ, Leisk GG, Bayan C, Georgakoudi I, Kaplan DL. Macromol Biosci. 2007; 7:643. [PubMed: 17477447]

25. Rockwood DN, Gil ES, Park SH, Kluge JA, Grayson W, Bhumiratana S, Rajkhowa R, Wang X, Kim SJ, Vunjak-Novakovic G, Kaplan DL. Acta Biomater. 2010 in press.

26. Meinel L, Betz O, Fajardo R, Hofmann S, Nazarian A, Cory E, Hilbe M, McCool J, Langer R, Vunjak-Novakovic G, Merkle HP, Rechenberg B, Kaplan DL, Kirker-Head C. Bone. 2006;

39:922. [PubMed: 16757219]

27. Agarwal N, Hoagland DA, Farris RJ. J Appl Polym Sci. 1997; 63:401.

28. Hu X, Kaplan D, Cebe P. Macromolecules. 2008; 41:3939.

29. Hu X, Kaplan D, Cebe P. Macromolecules. 2006; 39:6161.

30. Jung C. J Mol Recognit. 2000; 13:325. [PubMed: 11114067]

31. Tretinnikov ON, Tamada Y. Langmuir. 2001; 17:7406.

32. Hu X, Lu Q, Kaplan DL, Cebe P. Macromolecules. 2009; 42:2079.

33. Wilson D, Valluzzi R, Kaplan D. Biophysical Journal. 2000; 78:2690. [PubMed: 10777765]

34. Shen Y, Johnson MA, Martin DC. Macromolecules. 1998; 31:8857.

35. Asakura T, Kuzuhara A, Tabeta R, Saito H. Macromolecules. 1985; 18:1841.

36. Levin M. Trends Cell Biol. 2007; 17:261. [PubMed: 17498955]

37. Fukada E. Ferroelectrics. 1984; 60:285.

38. Fukada E. Ann NY Acad Sci. 1974; 238:7.

39. Fukada E. IEEE Trns Dielectr Electr Insul. 2006; 13:1110. 
40. Go Y, Ejiri S, Fukada E. Biochimica Et Biophysica Acta. 1969; 175:454. [PubMed: 5778181]

41. Fukada E, Takashit S. Japanese Journal of Applied Physics. 1971; 10:722.

42. Kim DK, Itoh T, Konishi T. Sen-I Gakkaishi. 1997; 53:365. 
Figure 1A

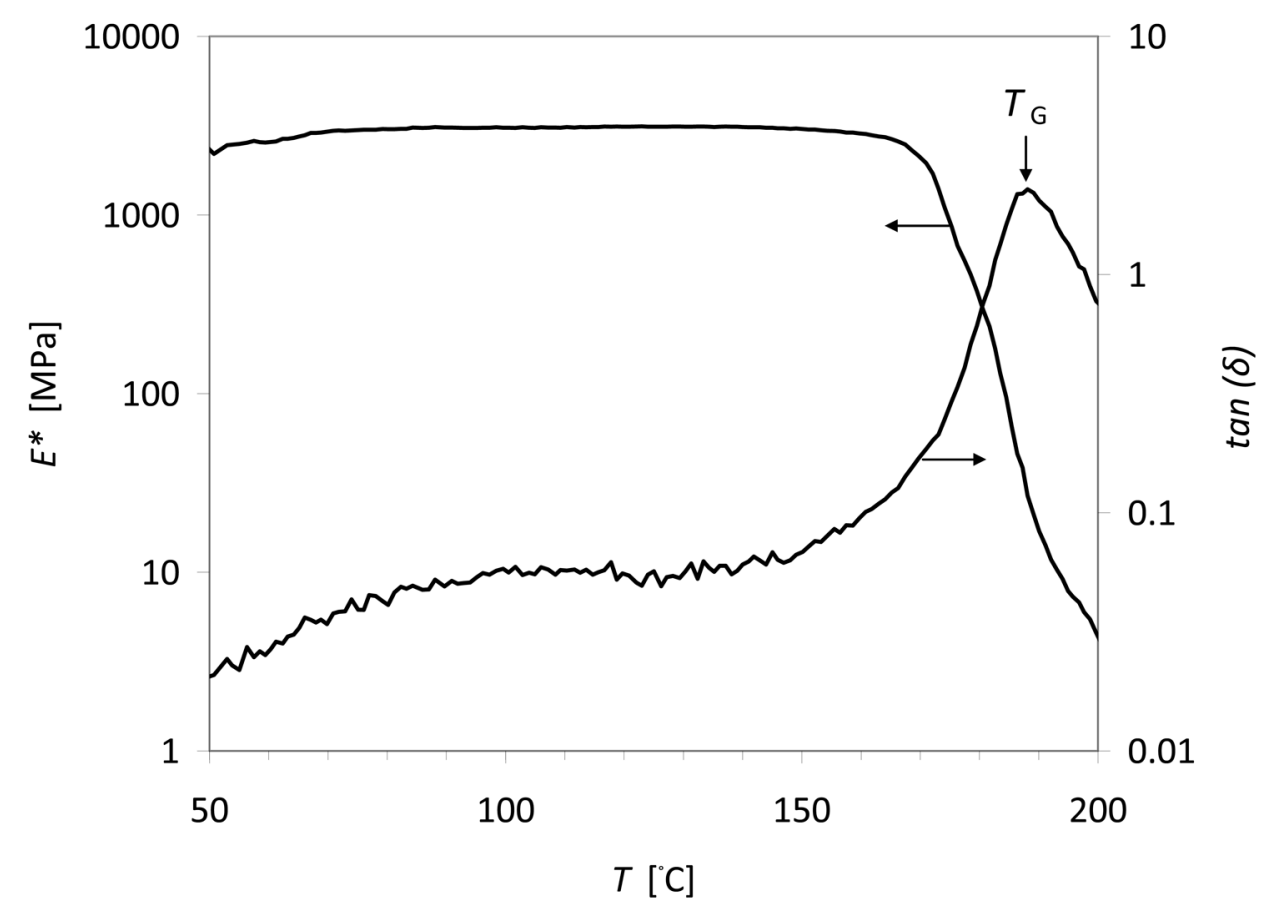

Figure 1B

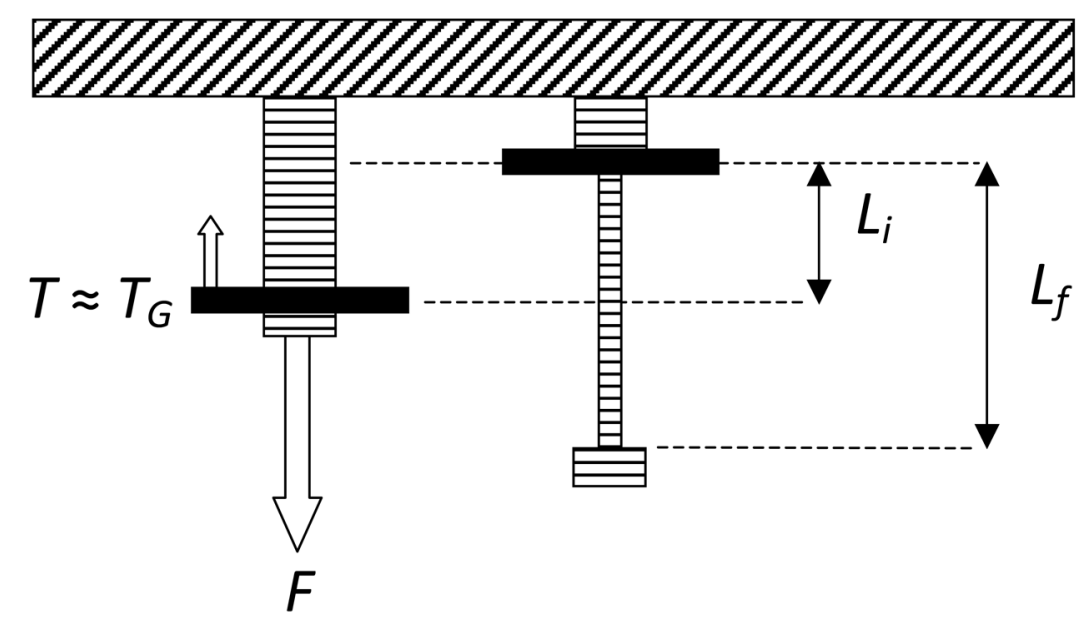

Silk film

Heating block

Figure 1.

Figure 1A DMA temperature sweep of the complex elastic modulus, $E^{*}$ and the loss tangent, $\tan (\delta)$ collected from a silk fibroin film $\left(T_{G} \approx 190^{\circ} \mathrm{C}\right)$. 
Figure 1B. Schematic of the zone-drawing setup. 
Figure 2A

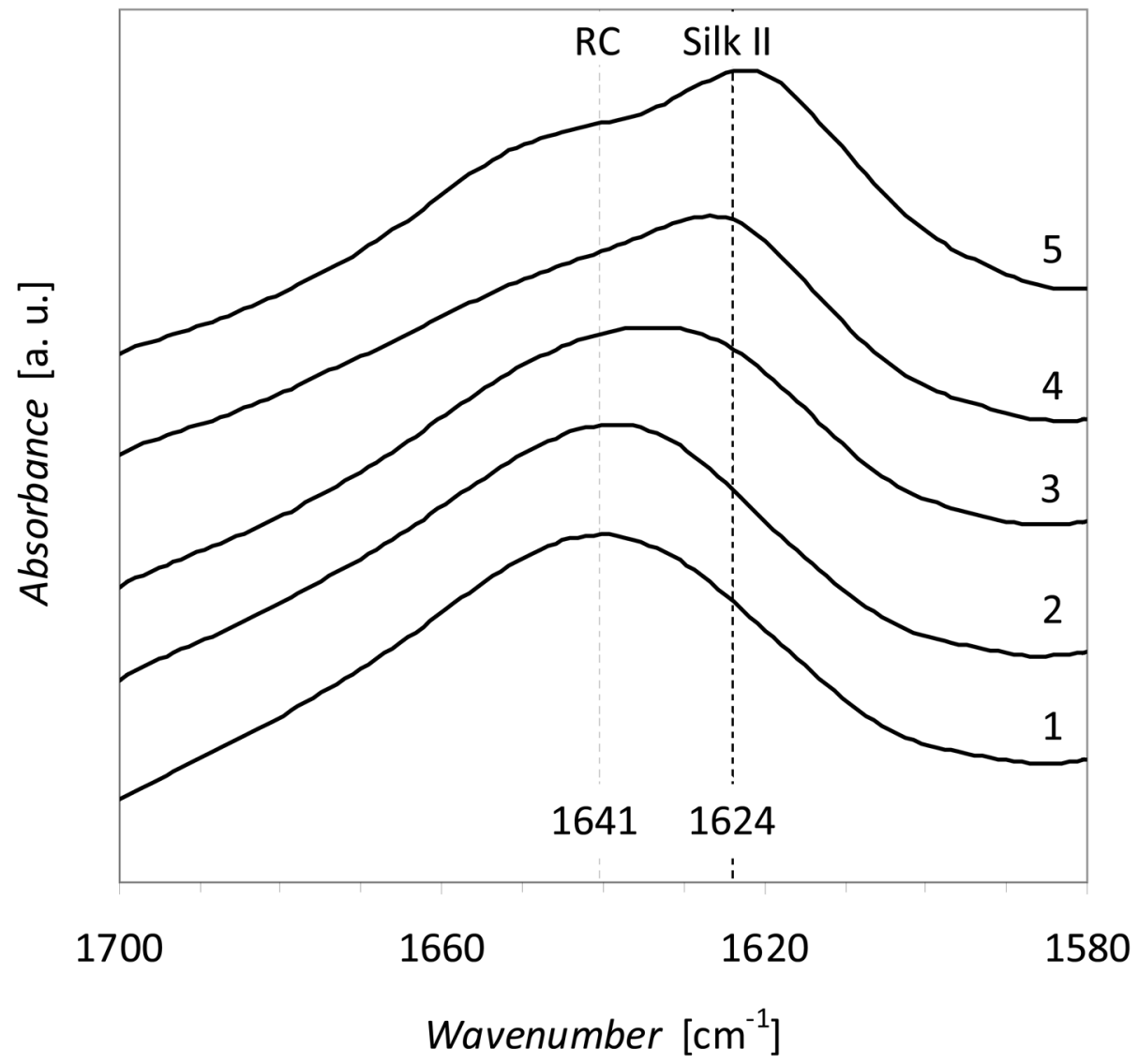

Figure 2B

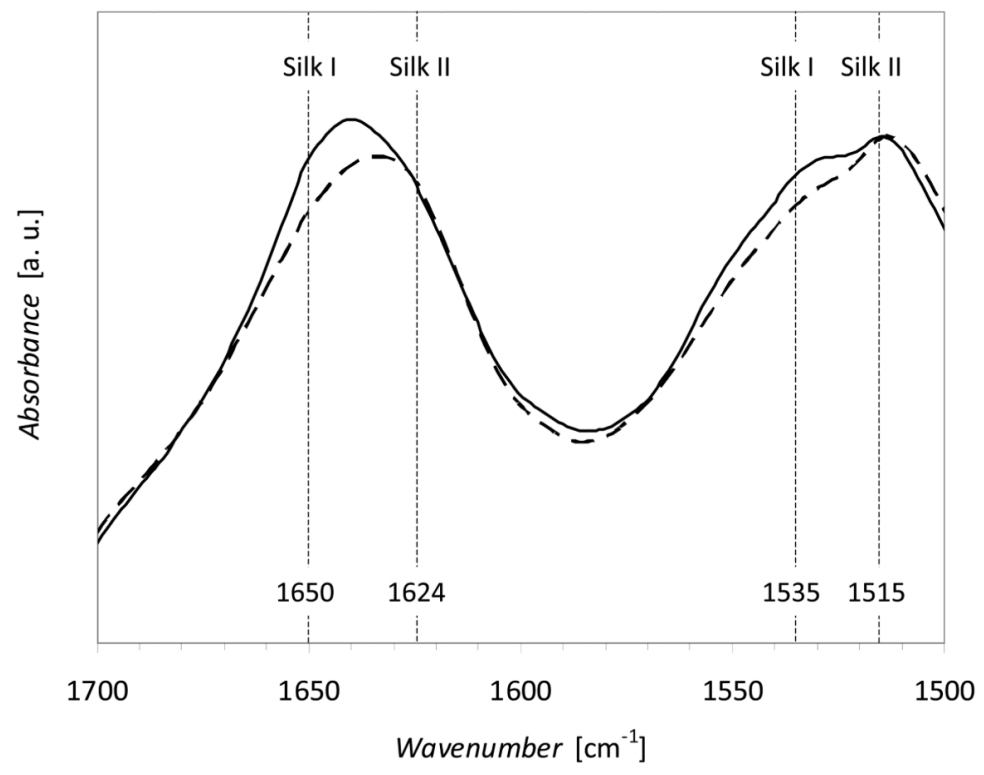

Figure 2.

Adv Funct Mater. Author manuscript; available in PMC 2013 January 16. 
Figure 2A. Amide I band of the FTIR spectra at different silk film draw ratios for zone drawing ( $\lambda=1.0,1.5,2.0$ and 2.7 for spectra labeled from 1 to 4 , respectively) and post zone-draw annealing at $200^{\circ} \mathrm{C}$ for one hour $(\lambda=2.0$, spectra 5$)$. RC denotes random coil structure.

Figure 2B. Amide I and amide II bands of the FTIR spectra for different draw methods (solid: water immersion drawing; dashed: zone drawing) at the same draw ratio of $\lambda=2.0$. 


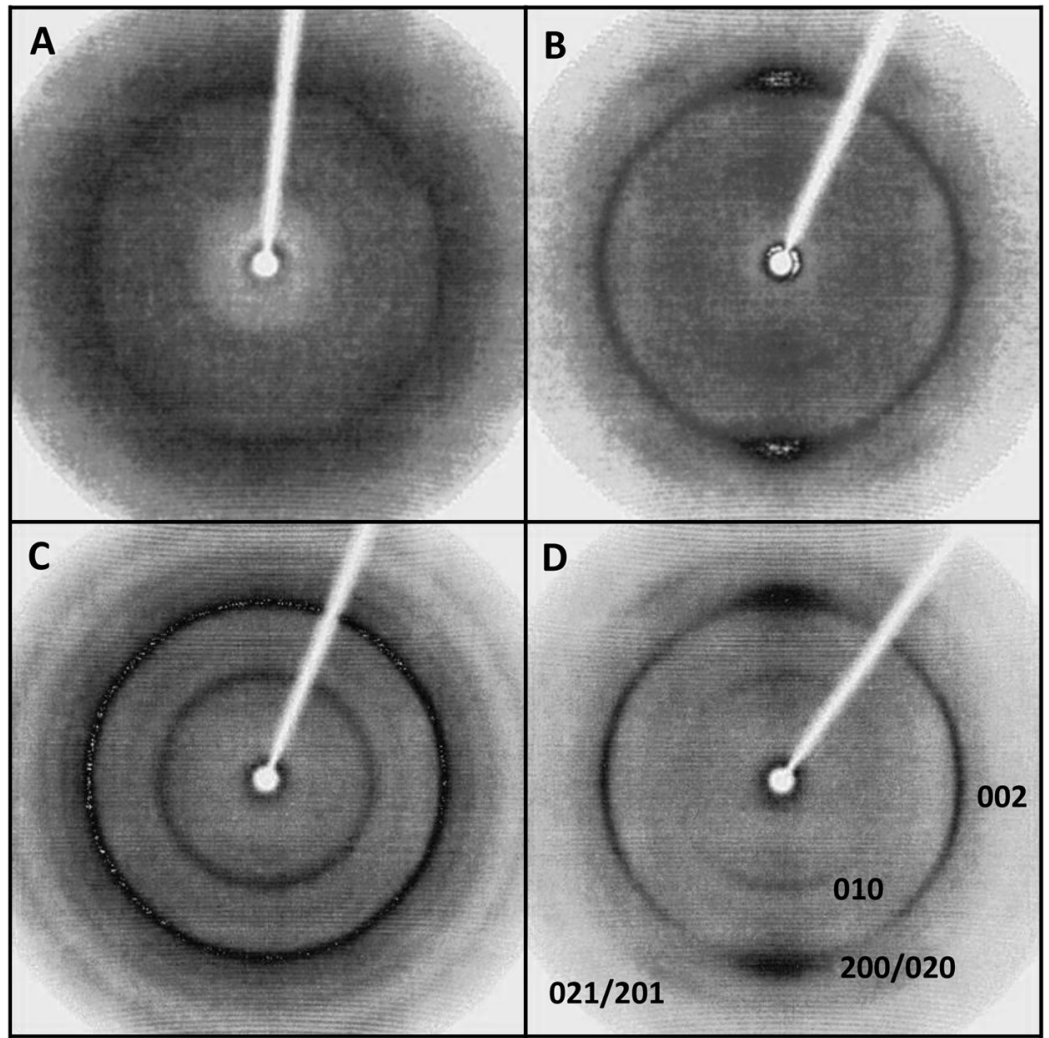

Figure 3.

2D-WAXD plots collected from (A) as-dried, (B) zone-drawn $(\lambda=2.7),(\mathbf{C})$ annealed $\left(200^{\circ} \mathrm{C}\right.$, one hour) and (D) zone drawn $(\lambda=2.7)$ and annealed $\left(200^{\circ} \mathrm{C}\right.$, one hour $)$ silk fibroin films. In (B) and (D), the draw direction is horizontal. Miller indices are included for crystal reflections in (D), according to [34]. 
Figure 4A

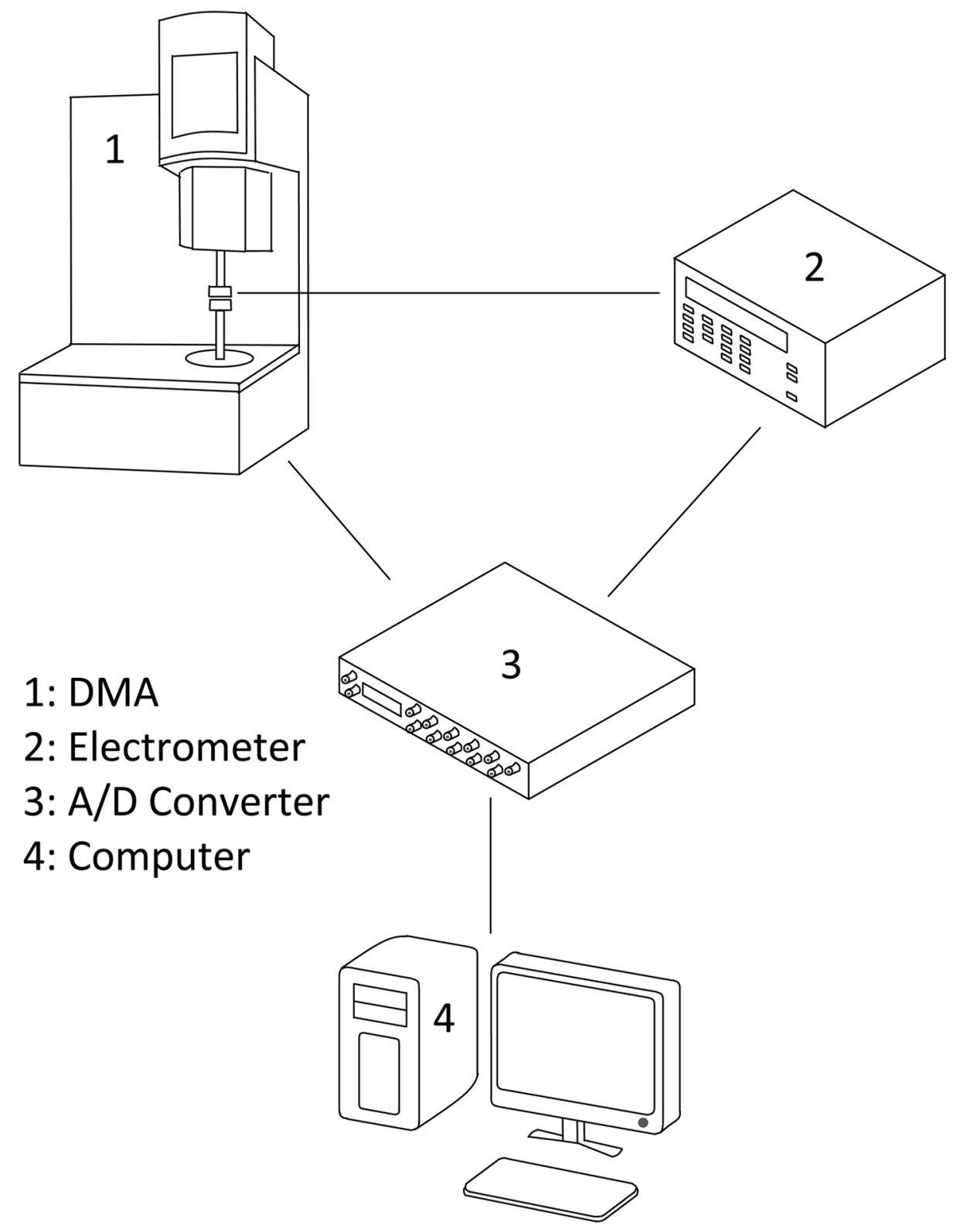


Figure 4B

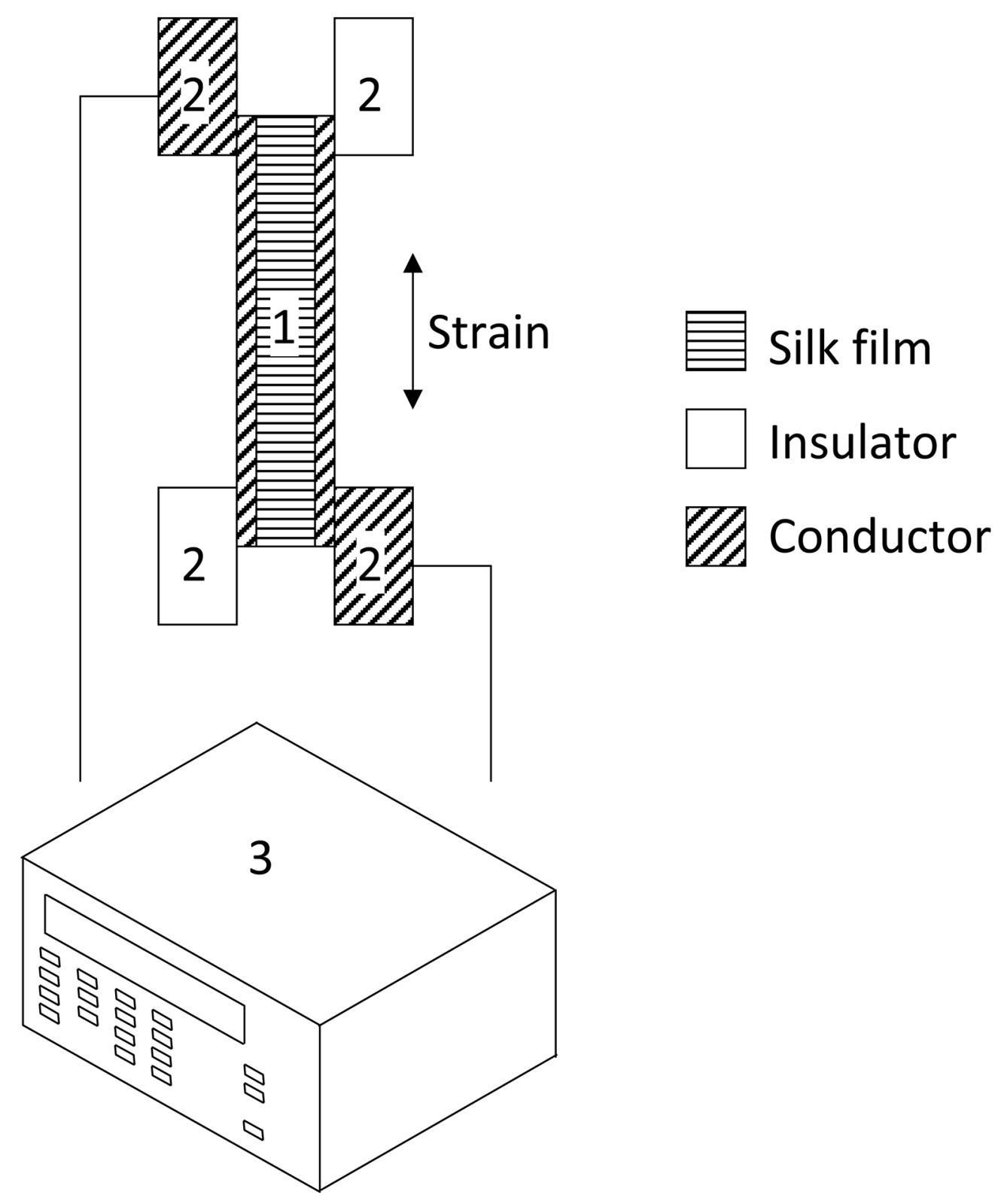




\section{Figure 4C}

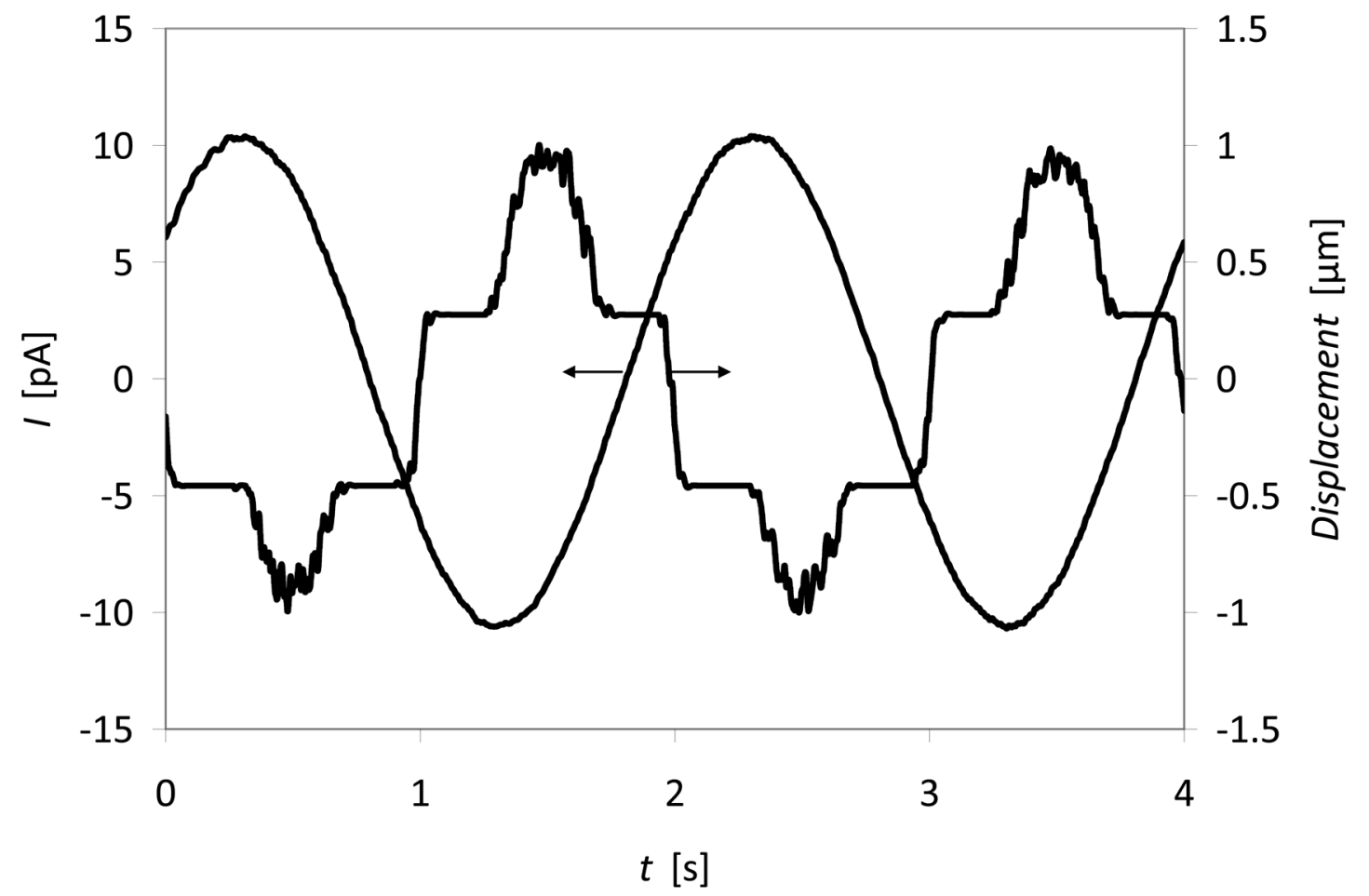

Figure 4.

Figure 4A. Schematic of the custom piezoelectric measurement setup: The strain signal from the DMA (1) and the current reading from the electrometer (2) were fed through an A/D converter (3) to a computer (4).

Figure 4B. Cross-sectional view of the silk film (1) placed between DMA fixtures (2) and the leads to the electrometer (3) for piezoelectric testing.

Figure 4C. Raw waveform data showing the sinusoidally applied displacement and the generated complex polarization for $\lambda=2.7$ and $\theta=\pi / 4$. 


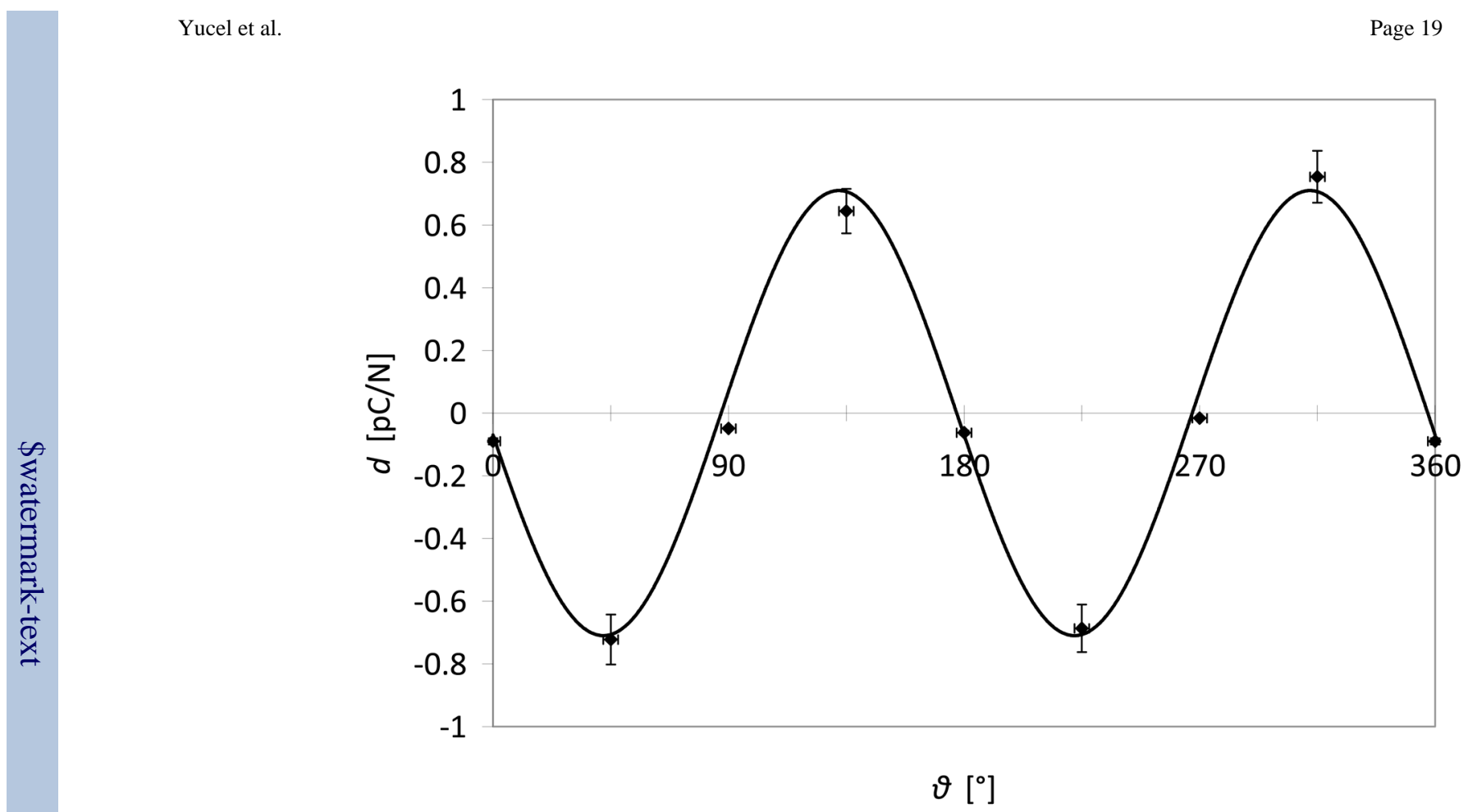

Figure 5.

Apparent piezoelectric response as a function of the measurement angle, $\theta$ for $\lambda=2.7(\mathrm{n}=3)$. 
Figure 6A

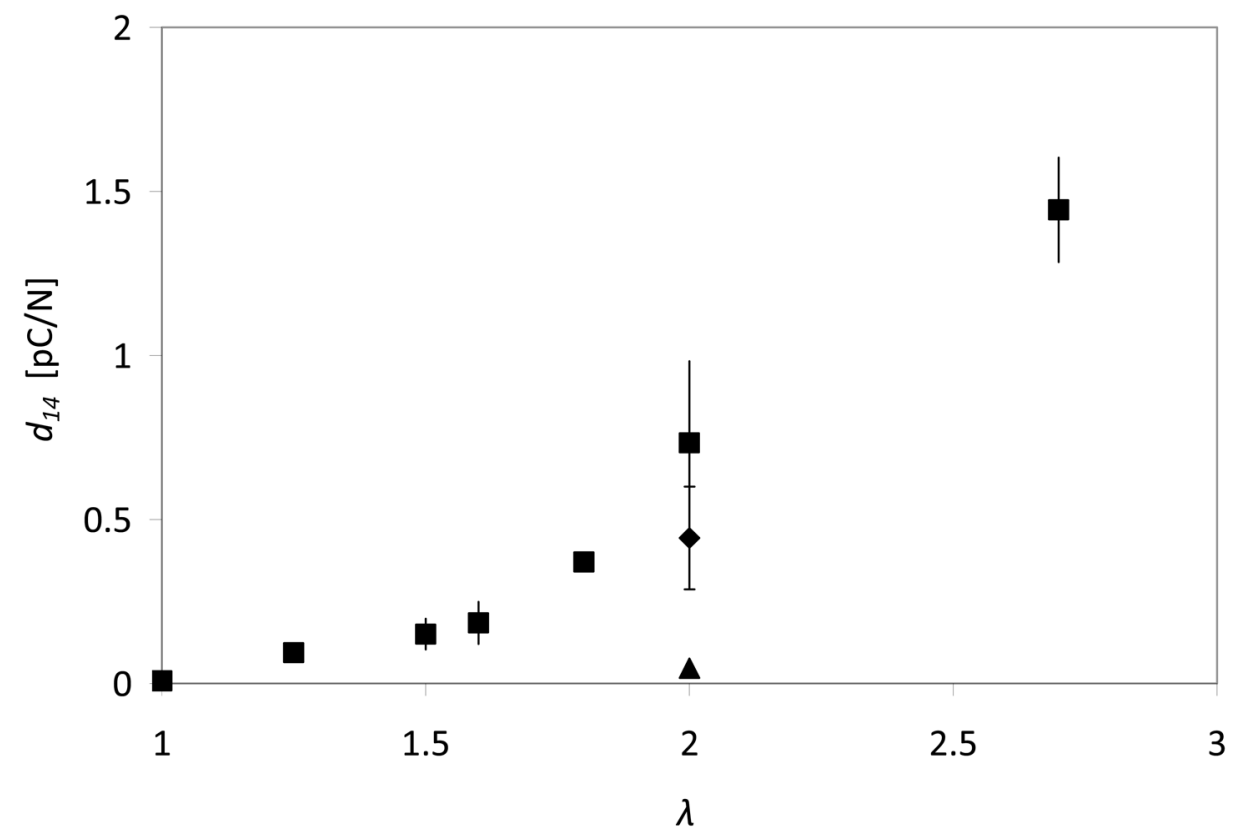

\section{Figure 6B}

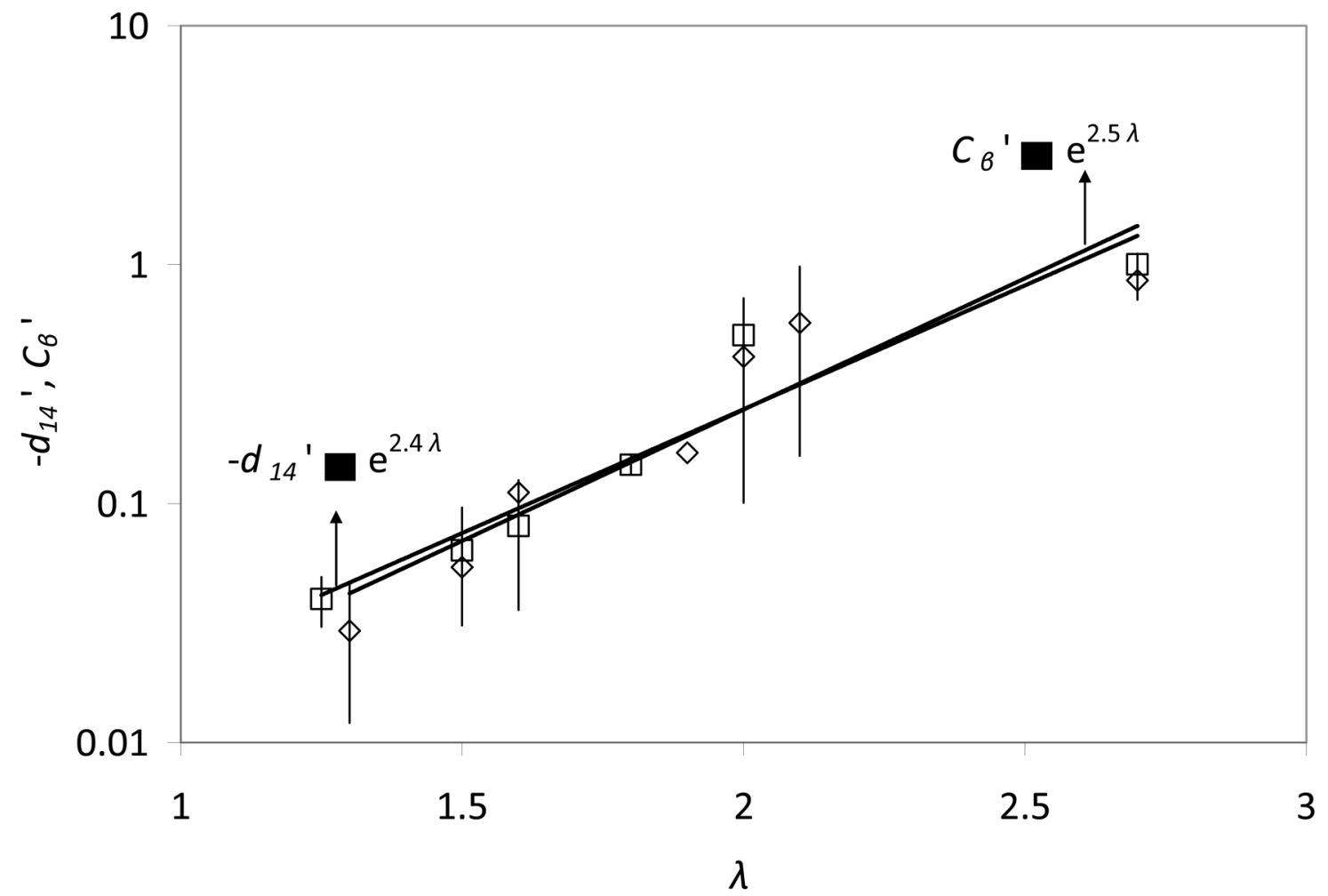

Adv Funct Mater. Author manuscript; available in PMC 2013 January 16. 
Figure 6.

Figure 6A. Shear piezoelectric coefficient $d_{14}$ as a function of the processing parameters (squares: zone drawn; triangle: water immersion drawn; diamond: methanol treated).

Figure 6B. Exponential dependence of $d_{14^{\prime}}$ and $C_{\beta^{\prime}}$ on the draw ratio. 


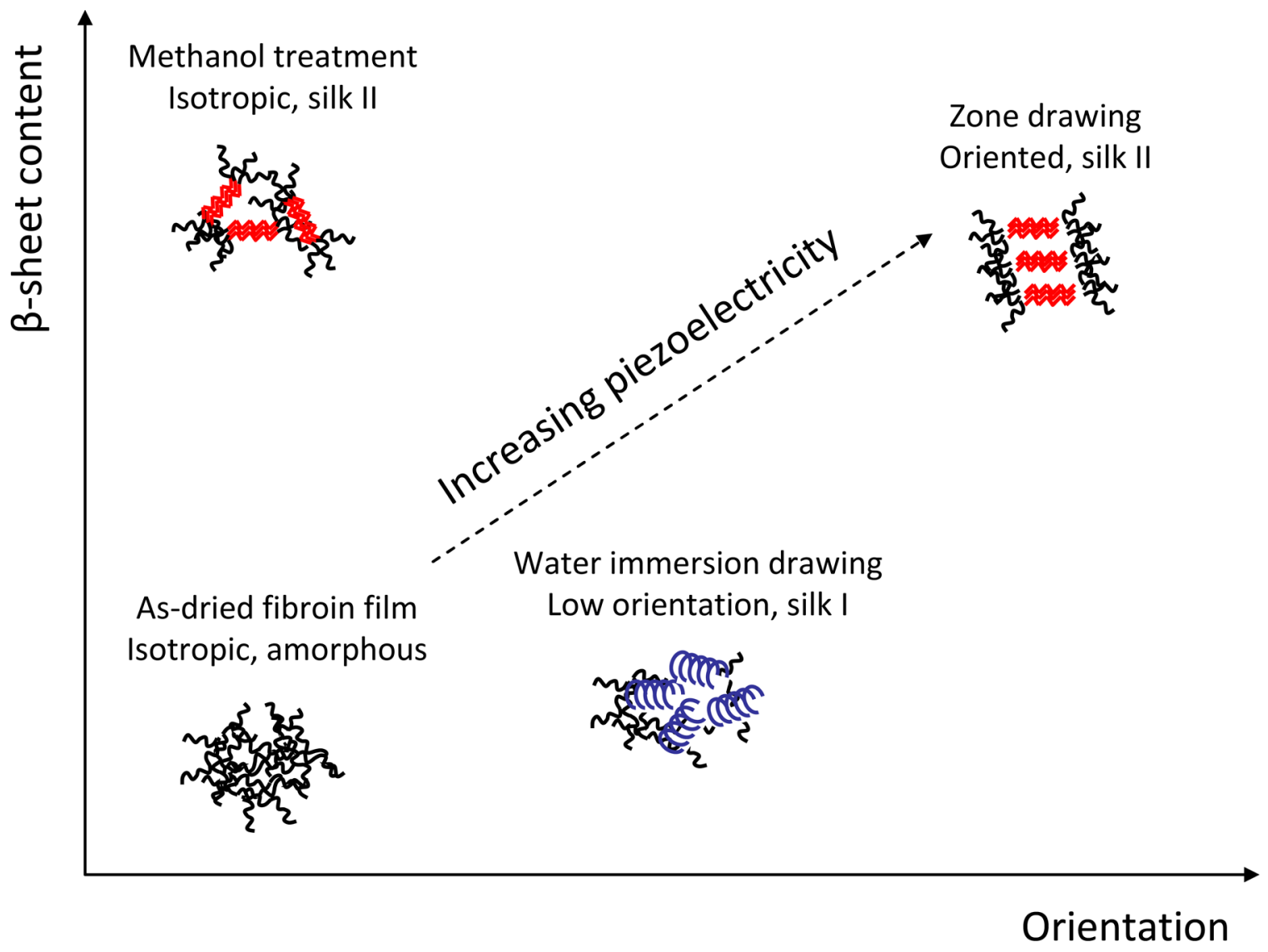

Figure 7.

Processing parameters, structure and piezoelectricity in silk fibroin. 